\title{
NDT of Rating Impact of Laser Padding on the Surface Layer
}

\author{
W. NAPAdŁeK ${ }^{a, *}$, M. Witoś ${ }^{b}$ And T. PRUSiK ${ }^{b}$ \\ ${ }^{a}$ Military University of Technology in Warsaw, S. Kaliskiego 2, 00-908 Warszawa, Poland \\ ${ }^{b}$ Air Force Institute of Technology, Księcia Bolesława 6, 01-494 Warszawa, Poland
}

\begin{abstract}
The article presents the problem of quality control the paramagnetic material of weld overlays laser made on ferro- and paramagnetic materials (steels, cast iron). To assess the quality of weld overlays paramagnetic material, and also the impact of overheating, besides laboratory researches on Keyence optical microscope, used measurement of existing magnetization of magnetic field distribution. Examples of test results by magnetic memory of metals are presented. It has been found, that is expedient use magnetic methods to assess the quality the microstructure of laser pad welded surface layer (influence of heat generation, microstructure changes, chemical composition and own stresses).
\end{abstract}

DOI: 10.12693/APhysPolA.133.707

PACS/topics: 81.05.Bx, 81.15.Fg, 03.75.Pp, 81.70.Ex, 81.70.Fy, 75.50.Bb, 06.20.-f, 06.60.Mr

\section{Introduction}

The surface layer of machine elements is usually shaped using mechanical (geometrical and surface) machining. Modern surface engineering technologies are also used, such as: ablative laser micromachining - Fig. 1, 3D and incremental technologies such a laser welding [1-3].The use of laser technology poses a challenge to existing nondestructive testing methods, for example, how to quickly monitor the quality of laser processing on ferromagnetic components?

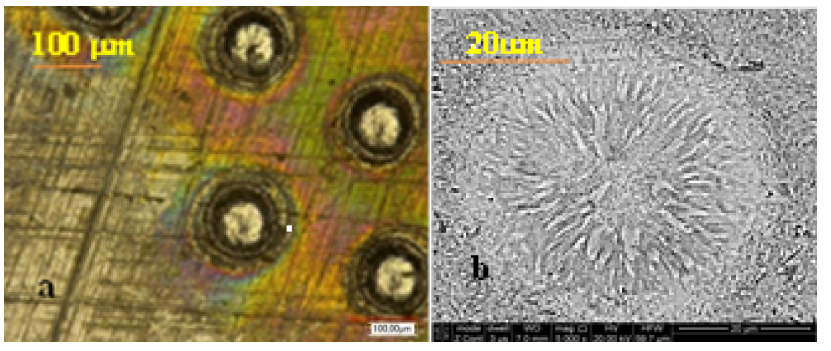

Fig. 1. Impact of surface laser texturing, visible micro craters $(\Phi<100 \mu \mathrm{m}, d<50 \mu \mathrm{m})$, a) surface discolouration caused by heat and b) changes in microstructure [3].

\section{Selection of non-destructive testing methods}

In order to control the surface layer of ferromagnetic materials and the quality of the laser treatment, is proposed an implicit relationship that exists between the chemical composition of the material, its structure, mechanical, and physical parameters. On the basis of the literature [4-12] was found that the magnetic and electrical parameters of the material are very sensitive diagnostic indicators, which is used in non-destructive magnetic tests. For initial research and atypical exploration

\footnotetext{
* corresponding author; e-mail wojciech.napadlek@wat .edu.pl
}

of research problems (assessment of microstructure and stress in industrial conditions), three research methods were used:

- measurement of magnetic anomalies using the Mageye [13] portable magnetic microscope, which is based on the Faraday magneto-optical effect $[14,15]$. The Mageye with optical resolution about $10 \mu \mathrm{m}$, field range $2 \mathrm{kA} / \mathrm{m}$ and magnetic resolution $50 \mathrm{~A} / \mathrm{m}$ (for magneto-optic sensor type A), was developed for the mobile quality inspection and management, and for the stray field visualization of: magnetic stripe cards - Fig. 2, magnetic encoders, welding seams, magnetic audio tapes, manipulated serial numbers, as well as dipole and multipole magnets;

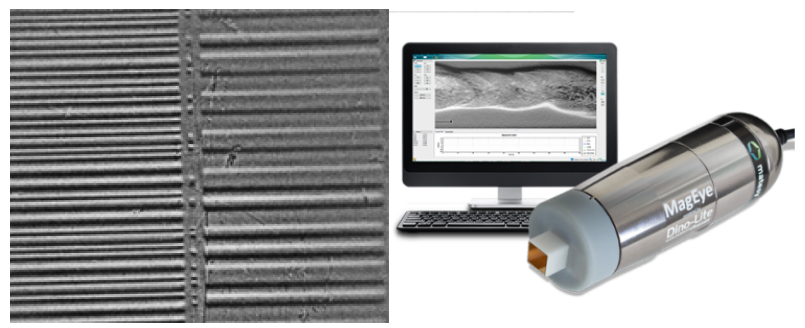

Fig. 2. Magnetic strip information and magnetogram of welding joint presented with MagEye microscope (post-processing: subtract errors of MO layer and CMOS matrix, enhance local contrast) [13].

- measurement of residual magnetization of samples, using a ruler of 16 triaxial magneto-impedance magnetometers (digital compass with field range $\pm 600 \mu \mathrm{T}$, resolution $0.6 \mu \mathrm{T}$ and $5 \mathrm{~mm}$ gap between magnetometers) $[5,16]$;

- precise measurement of the probe impedance $Z_{m}$ which maps the impedance of the probe without affecting test object $Z_{0}$, and inductivelly coupled probe from the material under test $\Delta Z[5,17-20]$. 


$$
Z_{m}=Z_{0}+\Delta Z=R+\mathrm{j} X
$$

Here the real part of impedance is the resistance $R$, and the imaginary parts is the reactance $X$.

\section{Research results}

\subsection{Measurements of magnetic anomalies on a micro} scale using a MagEye microscope

Results of measurements of non-uniform magnetic field on the surface layer illustrated in Fig. 3 and Fig. 4. Changing the polarization angle of the light on the magnetooptic layer (Faraday effect) under the influence of the external magnetic field was mapped in grayscale.

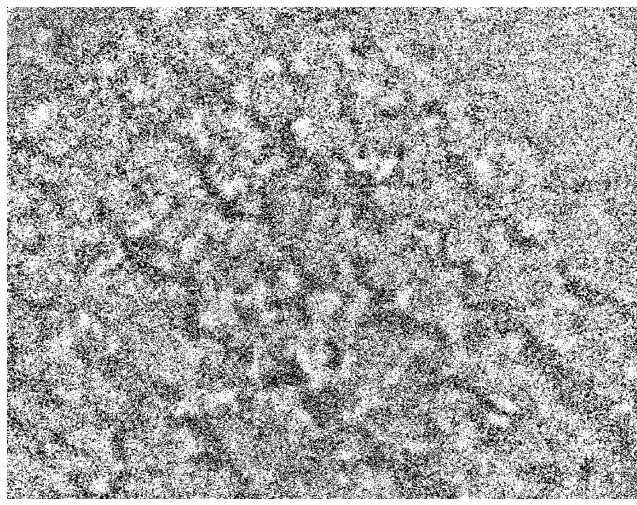

Fig. 3. Impact of surface corrosion products (oxide layers) on the existing unevenness of the magnetic field.

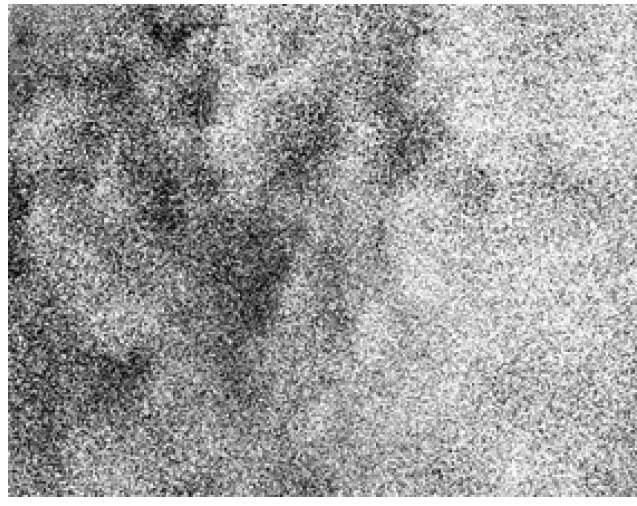

Fig. 4. Impact of surface laser treatment on the uneven distribution of the magnetic field (component perpendicular to the surface).

\subsection{Magnetometer measurements of the existing magnetic field distribution}

Within realized laboratory experiments made magnetometers measurements the existing magnetic field distribution, near ferromagnetic samples (with alloys of FeC) laser padded (multi-run and multilayer) type alloy Stellite Co-6 powder (paramagnetic material). View of the sample and measurement of the magnetized presence shown in Fig. 5.

The results of the measurements is dominated by the following impact:
- average magnetic properties of material and sample shape (demagnetisation tensor, edge effect;

- mechanical stresses introduced into the material during the cutting samples;

- thermal stresses in zones of overheating of the structure;

- apertures and spatial characteristics of magnetometers (a problem omitted in the description of the magnetic memory metal method).

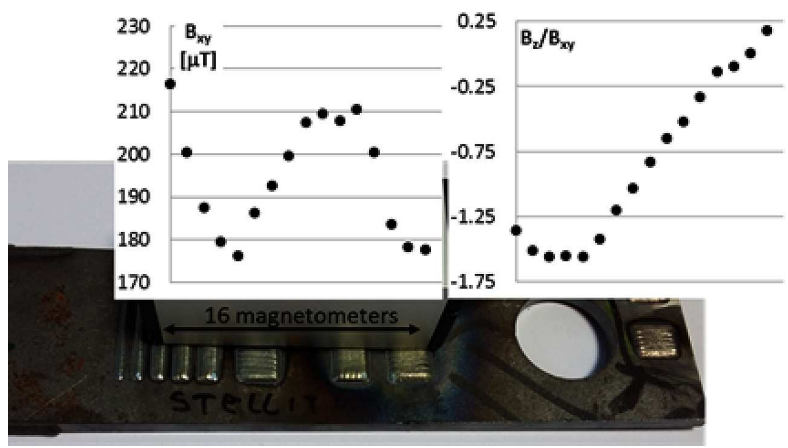

Fig. 5. Existing magnetization samples laser padded by powders Stellite (the distance of magnetometers from the sample surface $3.5 \mathrm{~mm}$ ); $\mathrm{B}_{x y}$ - magnetic horizontal component, $\mathrm{B}_{z}$ - component magnetic field perpendicular to the surface.

\subsection{Measurement of surface impedance}

Sample results of surface impedance measurement of a sample, made of ferromagnetic structural steel, padded with Stellite Co-6 alloy powder, shown in Fig. 6. The sample surface around the padding weld is covered by a layer of iron oxide products - products of surface corrosion and laser ablation. The average resonance frequency of the $\mathrm{LC}$ circuit was $3.4 \mathrm{MHz}$ the visual measurement result in the time domain maps the resulting impact:

- substrate material,

- paramagnetic parameters of Stellite powder and areas of laser surface cleaning (clear zone LO),

- edge effects,

- scan speed.

Based electromagnetic research, the possibility of reliable control of the surface layer parameters and the influence of laser processing parameters was found. Measurements should be made with the scanning head, due to the very strong influence (on the measurement result) of the coil distance from the surface to be tested. Changing the single-row distance $\mu \mathrm{m}$ already affects the measurement result! 


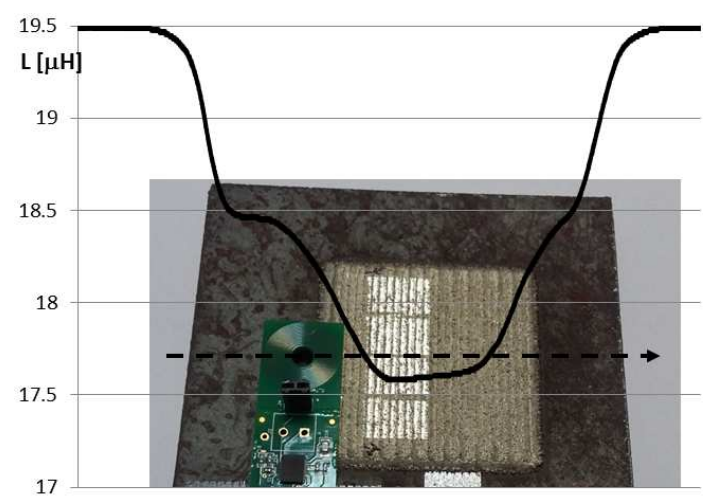

Fig. 6. Changing inductance of the parallel LC circuit coupled inductively with the test material (the distance of the coil from the ferromagnetic substrate $4 \mathrm{~mm}, v=$ $0.05 \mathrm{~m} / \mathrm{s}, f s=1 \mathrm{kHz}, \mathrm{DUT}$ - a device under testing).

\section{Comments}

Based on preliminary research shown, that magnetic field measured near the test piece, may be a reliable carrier for the quality of the surface layer of the material and the local thermal stresses, introduced into the material by laser treatment. It is necessary to perform a comparative study of microstructure to develop diagnostic criteria.

Based on laboratory tests, was found that:

- The idea of digital recording and visualization of magnetic field distribution using magnetooptic layers and CMOS optical converters, with high resolution, is particularly promising for NDE applications, used to control the quality of the surface layer and the laser machining process (including spot assessment of the impact of heat and micro craters). Sensitivity of magnetooptic layer A in the MagEye tested microscope was insufficient $(\mathrm{SNR}<12 \mathrm{~dB})$ to identify microstructure changes without material demagnetization. The authors recommend, however, the magnetization of the test surface and differential analysis, to minimize the negative impact of simplification in the optical path of the MagEye microscope, as well as improving the reliability of the test results.

- Three-axis magnetometers provide quantitative and qualitative information about the distribution of the magnetic field near the examined element. Cheap digital compasses provide reliable test results and they can be used to control the quality of the surface layer, as well as non-destructive testing.

- Impedance measurements provide reliable information about magnetic properties (magnetic permeability), as well as the electrical (conductivity) of the surface layer of the material. For proper spatial resolution measurements, it is necessary to optimize the geometry of the coil, its distance from the surface to be measured, as well as scanning speed.

\section{Summary}

Modern metrological possibilities and dynamic development of microelectronics opens new opportunities for magnetic and electromagnetic surveys in area of quality control, non-destructive testing and monitoring the technical condition of critical structural elements.

At the next stage of research will be the integration and optimization of NDE methods.

\section{Acknowledgments}

This work was supported by the project funded by the National Centre for Research and Development Project PBS3/B5/37/2015.

\section{References}

[1] Y.Y. Özbek, T.Gökkaya, C.V. Yavaşcan, Acta Phys. Pol. A 129, 588 (2016).

[2] B. Grabas, Sz. Tofil, W. Napadłek, Arch. Metall. Materials 61, 1163 (2016).

[3] W. Napadłek, Materials Testing 57, (2015).

[4] D.J. Craik, M.J. Wood, J. Appl. Phys. D: Appl. Phys. 3, 1009 (1970).

[5] The Web's Largest Open Access Database of Nondestructive Testing (NDT).

[6] M. Witos, M. Zieja, B. Kurzyk, e-J. Nondestr. Test. 21, (2015).

[7] W-K. Tse, A.H. MacDonald, Phys. Rev. B84, 205327 (2011).

[8] C. Krell et al. J. Magn. Magn. Mater. 215, 63 (2000).

[9] S. Woodford, PhD Thesis, Kapstadt, South Afrika 2008.

[10] M. Iwaniec et al., Solid State Phenomena 208, 70 (2014).

[11] M. Stolzenberg et al., Online material Characterisation at Strip Production(OMC), Final report EUR25879EN Research Fund for Coal, Steel, Directorate-General for Research, Innovation European Commission, 2014.

[12] G. Dobmann in: Nuclear Power-Control, Reliability, Human Factor, Ed. P. Tsvetkov, INTECH, Rijeka 2011, p. 311.

[13] Matesy GmbH - Magnetische Technologien und Systeme.

[14] K. Barczak el al., Acta Phys. Pol. A 118, 1090 (2010).

[15] P. Gretchen, PhD Thesis, University of Kentucky 2014, Paper 15.

[16] M. Witos, PIRE (2014).

[17] Impedance Measurement Handbook. A Guide to Measurement Technology, Techniques, 6th ed., Keysight Technologies, 2016.

[18] Z.H. Żurek, RLC circuit for material testing, NDT, KOMEL 2015.

[19] Z.H. Żurek, M. Witos, e-J. Nondestr. Test. 21 (2016).

[20] M. Witos, M. Roskosz, K. Fryczowski, Autobusy: technika, eksploatacja, systemy transportowe $\mathbf{1 2}$, (2016), (in Polish). 